\title{
UMEDECIMENTO DO SUBSTRATO E TEMPERATURA NA GERMINAÇÃO E VIGOR DE SEMENTES DE Amburana cearensis (All.) A.C. Smith ${ }^{1}$
}

\author{
ROBERTA SALES GUEDES ${ }^{2}$, EDNA URSULINO ALVES ${ }^{3}$, EDILMA PEREIRA GONÇALVES ${ }^{4}$, \\ JEANDSON SILVA VIANA ${ }^{4}$, PABLO RADAMÉS CABRAL DE FRANÇA ${ }^{5}$, COSMO RUFINO DE LIMA ${ }^{5}$
}

\begin{abstract}
RESUMO - A Amburana cearensis (Allemão) A.C. Smith é uma espécie que apresenta considerável importância econômica para região de Caatinga e é empregada na medicina popular. Atualmente, há necessidade de padronização do teste de germinação nos laboratórios de análises; nesse sentido a definição do volume de água e de temperatura que favoreça a germinação, conforme a espécie, provavelmente minimizaria as variações nos resultados deste teste. O presente trabalho foi conduzido com o objetivo de avaliar diferentes volumes de água no substrato e temperaturas para a germinação de sementes de $A$. cearensis. As sementes foram semeadas em papel toalha umedecido com volume de água equivalente a 2,$0 ; 2,5 ; 3,0$ e 3,5 vezes o peso do substrato, sem adição posterior de água, e mantidas em germinadores (B.O.D.) nas temperaturas constantes de $30{ }^{\circ} \mathrm{C}$ e $35^{\circ} \mathrm{C}$. Foi analisada a porcentagem de germinação, a primeira contagem de germinação, o índice de velocidade de germinação, o comprimento e a massa seca de plântulas. $O$ delineamento experimental foi o inteiramente ao acaso com os tratamentos em esquema fatorial 4 × 2 (volumes de água e temperaturas). A temperatura de $35^{\circ} \mathrm{C}$ prejudicou a germinação e o vigor das sementes de A. cearensis. A temperatura de $30{ }^{\circ} \mathrm{C}$ e o volume de água de 3,5 vezes o peso do papel é a combinação mais indicada para a condução dos testes de germinação e vigor das sementes de $A$. cearensis.
\end{abstract}

Termos para indexação: cumaru, sementes florestais, disponibilidade de água, análise de sementes.

\author{
SUBSTRATE MOISTURE AND TEMPERATURE IN THE GERMINATION AND \\ VIGOR OF Amburana cearensis (All.) A.C. Smith SEEDS
}

\begin{abstract}
Amburana cearensis (Allemão) A.C. Smith is an important economic species of the Brazilian Caatinga and in popular medicine and germination test procedures for laboratory analyses need to be standardized. The objective of this study was to evaluate the effects of different water volumes in the substrate and also temperatures on $A$. cearensis germination. The seeds were sown in paper towels wetted with the water equivalent of $2.0 ; 2.5 ; 3.0$ and 3.5 times the substrate weight. No more water was added and the seeds were maintained in chambers at constant temperatures of $30{ }^{\circ} \mathrm{C}$ and $35^{\circ} \mathrm{C}$. The following parameters were analyzed: the germination percentage, first count germination, index of germination speed, length and dry mass of seedlings. A completely randomized design was used with a $4 \times 2$ factorial (water volumes and temperatures). The $35^{\circ} \mathrm{C}$ temperature
\end{abstract}

\footnotetext{
${ }^{1}$ Submetido em 11/11/2009. Aceito para publicação em 24/03/2010. Parte da Dissertação de Mestrado do primeiro autor apresentada ao CCA/UFPB.

${ }^{2}$ Bióloga, doutoranda do Departamento de Fitotecnia, CCA/UFPB, CP 02, Cep: 58397-000, Areia, PB. E-mail: roberta biologa09@yahoo.com.br.
}

${ }^{3}$ Eng. Agr., Dr., Profa. Titular, Departamento de Fitotecnia, CCA/UFPB, e-mail: ednaursulino@cca.ufpb.br - Caixa Postal 02, cep: 58397-000,
Areia - PB.

${ }^{4}$ Eng. Agr., Drs., Profs. Titulares, Unidade Acadêmica de Garanhuns, UAG/UFRPE, Av. Bom Pastor, SN, Boa Vista, 55296-901, Garanhuns PE.edilmapg@hotmail.com.

${ }^{5}$ Eng. Agr., mestrando do Departamento de Fitotecnia, CCA/UFPB, CP. 02, Cep: 58397-000, Areia-PB. pabloradames@hotmail.com 
impaired the germination and vigor of $A$. cearensis seeds. A temperature of $30^{\circ} \mathrm{C}$ and a water volume of 3.5 times the weight of paper is the most suitable combination for doing germination tests and evaluating the vigor of $A$. cearensis seeds.

Index terms: cumaru, forest seeds, water availability, seed analysis.

\section{INTRODUÇÃO}

Amburana cearensis (Allemão) A.C. Smith é uma espécie popularmente conhecida como cumaru, cerejeira ou imburana-de-cheiro que pertence à família Fabaceae. A espécie apresenta propriedades medicinais, sendo a casca da árvore e as sementes utilizadas na produção de medicamentos populares, destinadas ao tratamento de afecções pulmonares, tosses, asma, bronquite e coqueluche (Lorenzi e Matos, 2002).

Das cascas do caule já foram isoladas várias substâncias, incluindo cumarina, isocampferídio, fisetina, alfalona e amburosídio A, que estão relacionadas às atividades antinociceptiva, antiinflamatória e relaxante muscular (Canuto, 2002). Além disso, suas sementes são utilizadas comercialmente na perfumaria (Bezerra et al., 2005).

A árvore é muito ornamental, principalmente pelos ramos e tronco de cor vinho ou marron-avermelhado e da árvore é extraída excelente madeira a qual é empregada para mobiliário fino, lambris, balcões, folhas fraqueadas decorativas, tanoaria, esculturas e marcenaria em geral (Lorenzi, 2002) e, devido a estas qualidades, tem sido explorada nos locais de ocorrência até a exaustão, estando listada como espécie ameaçada de extinção (IBAMA, 2008).

O conhecimento das condições apropriadas que viabilize a condução do teste de germinação em laboratório de sementes de uma dada espécie é imprescindível, principalmente pelas respostas diferenciadas que podem apresentar devido a diversos fatores como dormência, volume de água, luz, temperatura, oxigênio e ocorrência de agentes patogênicos associados ao tipo de substrato para sua germinação (Brasil, 1992; Carvalho e Nakagawa, 2000).

Os limites da temperatura de germinação fornecem subsídios de interesses biológico e ecológico, auxiliando os estudos ecofisiológicos e de sucessão vegetal (Figliolia et al., 1993). A temperatura afeta a porcentagem, velocidade e uniformidade de germinação e está relacionada com os processos bioquímicos (Carvalho e Nakagawa, 2000). As sementes apresentam comportamento variável em diferentes temperaturas, não havendo uma temperatura ótima e uniforme de germinação para todas as espécies. Em geral, a temperatura é chamada ótima quando ocorre a máxima germinação, no menor tempo.

Da mesma forma que a temperatura, a umidade do substrato constitui um dos fatores essenciais para desencadear o processo germinativo (Carvalho e Nakagawa, 2000) e este deve permanecer uniformemente úmido nos testes de germinação conduzidos em laboratório, de modo que garanta a germinação e o desenvolvimento das plântulas.

A falta ou excesso de umidade no substrato pode resultar em efeito negativo sobre a germinação (Carvalho e Nakagawa, 2000). E, embora seja preconizada a adição subsequente de água durante o teste de germinação, deve ser evitada sempre que possível, pois pode provocar um aumento na variabilidade entre as repetições e entre os testes (Coimbra et al., 2007). O analista deve observar diariamente os substratos e adicionar água somente em casos extremos.

E além de contribuir na área de tecnologia de sementes florestais, nas análises laboratoriais de rotina, o umedecimento do substrato dará respostas eficazes no planejamento para recuperação de áreas degradadas por considerar os fatores ecológicos da espécie, indicando se as mesmas serão implantadas em áreas de clareiras (com menor disponibilidade hídrica) ou mais sombreadas (com maior disponibilidade hídrica).

A padronização do volume de água que favoreça a germinação, conforme a espécie, provavelmente minimizaria as variações nos resultados dos testes de germinação. Pesquisas sobre as exigências de água em sementes são pioneiras, estando disponíveis informações sobre poucas espécies florestais, tais como: Dinizia excelsa Ducke (Varela et al., 2005), Ochroma pyramidale (Cav. ex Lam.) Urban (Ramos et al., 2006a), Schizolobium amazonicum Huber ex Ducke (Ramos et al., 2006b) e Parkia platycephala Benth. (Gonçalves et al., 2008). Também são encontradas algumas pesquisas com espécies agrícolas, como amendoim (Tanaka et al., 1991), algodão (Novembre e Marcos Filho, 1999) e maxixe (Gentil e Torres, 2001).

Considerando a importância da temperatura e disponibilidade hídrica no substrato para que ocorra a germinação das sementes e formação de plântulas, bem 
como no processo de propagação das espécies florestais, procurou-se avaliar o efeito da temperatura e de diferentes volumes de água no substrato na germinação das sementes e no vigor das plântulas de Amburana cearensis.

\section{MATERIAL E MÉTODOS}

Foram utilizadas sementes de Amburana cearensis coletados manualmente em oito matrizes no início do processo de deiscência dos frutos, no município de Patos - PB. Depois de coletadas, as sementes foram beneficiadas por meio de debulha manual e mantidas em laboratório, à sombra, para secagem natural por cinco dias. Em seguida foram realizados os seguintes testes e determinações:

No teste de germinação as sementes foram distribuídas no substrato papel toalha, o qual foi organizado na forma de rolo e umedecido com volumes de água equivalentes a 2,$0 ; 2,5 ; 3,0$ e 3,5 vezes o peso do substrato seco, sem adição posterior de água, sendo utilizadas três folhas por rolo. Para cada tratamento, utilizaram-se quatro repetições de 25 sementes. Os rolos foram acondicionados em sacos de plástico, transparente, de $0,04 \mathrm{~mm}$ de espessura, com a finalidade de evitar a perda de água por evaporação.

O teste de germinação foi conduzido em germinadores tipo B.O.D. regulados para os regimes de temperaturas constantes de $30^{\circ} \mathrm{C}$ e $35^{\circ} \mathrm{C}$, com fotoperíodo de oito horas, utilizando lâmpadas fluorescentes tipo luz do dia (4 x $20 \mathrm{~W})$. As avaliações foram efetuadas diariamente após a instalação do teste, por um período de 21 dias, quando o experimento foi encerrado. As contagens foram realizadas diariamente, considerando-se como sementes germinadas aquelas que emitiram a raiz primária e o parte aérea e se encontravam aparentemente sadias. Os resultados foram expressos em porcentagem.

Para avaliar o vigor das sementes submetidas aos diferentes tratamentos realizaram-se as seguintes determinações: primeira contagem de germinação, índice de velocidade de germinação, bem como o comprimento de plântulas e a massa seca de plântulas. A primeira contagem de germinação foi conduzida conjuntamente com o de germinação, onde se computou o número de sementes germinadas logo após a sua germinação (10 dias), sendo os dados expressos em percentagem.

$O$ índice de velocidade de germinação foi avaliado conjuntamente com o teste de germinação onde foram realizadas contagens diárias, durante 21 dias, das sementes germinadas e, o índice de velocidade de germinação, sendo calculado empregando-se a fórmula proposta por Maguire
(1962), onde, sendo: $I V G=\frac{\mathrm{G}_{1}}{N_{1}}+\frac{\mathrm{G}_{2}}{N_{2}}+\ldots+\frac{\mathrm{G}_{\mathrm{n}}}{N_{n}}$ sendo: $\mathrm{G}_{1}, \mathrm{G}_{2}$ e $\mathrm{G}_{\mathrm{n}}=$ número de plântulas normais computadas na primeira, na segunda e na última contagem; $\mathrm{N}_{1}, \mathrm{~N}_{2}$ e $\mathrm{N}_{\mathrm{n}}=$ número de dias da semeadura à primeira, segunda e última contagem.

No final do teste de germinação (21 dias) as plântulas normais de cada repetição foram medidas da raiz até a parte aérea, usando-se uma régua graduada em centímetros, sendo os resultados expressos em cm/plântula. Para determinação da massa seca de plântulas foram utilizadas as mesmas plântulas da avaliação anterior, as quais foram colocadas (sem os cotilédones) em sacos de papel Kraft e levados à estufa regulada a $65^{\circ} \mathrm{C}$ até atingir peso constante ( 48 horas) e, decorrido esse período, as amostras foram pesadas em balança analítica com precisão de $0,001 \mathrm{~g}$, sendo o peso obtido, por repetição, dividido pelo número total de plântulas normais, com os resultados expressos em g/plântula.

O delineamento experimental realizado foi inteiramente ao acaso, com os tratamentos distribuídos em esquema fatorial 4 × 2 (volumes de água no substrato x temperatura), com 4 repetições de 25 sementes para cada tratamento. Os dados, não transformados, foram submetidos à análise de variância, utilizando-se o teste $\mathrm{F}$ para comparação dos quadrados médios e as médias comparadas pelo teste de Scott - Knott com $p>0,05$. Para os efeitos quantitativos foi realizada análise de regressão polinomial.

\section{RESULTADOS E DISCUSSÃO}

Na Figura 1 encontram-se os dados das porcentagens de germinação, obtidas de acordo com as temperaturas e volumes de água no substrato para as sementes de Amburana cearensis. Os resultados obtidos com as sementes submetidas aos volumes de água equivalentes a 2,$0 ; 2,5 ; 3,0$ e 3,5 vezes o peso do papel e as temperaturas de $30{ }^{\circ} \mathrm{C}$ e $35{ }^{\circ} \mathrm{C}$ indicaram que as interações entre esses fatores exerceram influência sobre as porcentagens de germinação das sementes de $A$. cearensis. Estes resultados não corroboram com os mencionados por Tanaka et al. (1991), para Arachis hypogaea; por Varela et al. (2005), para Dinizia excelsa Ducke; e por Gonçalves et al. (2008) para Parkia platycephala Benth., segundo os quais os diferentes volumes de água no substrato não interferem significativamente nas porcentagens de germinação.

O maior percentual de germinação $(94 \%)$ foi obtido com sementes na temperatura de $30{ }^{\circ} \mathrm{C}$ e com o volume de água de 3,25 vezes o peso do substrato seco, no entanto a 
partir deste volume a germinação foi afetada negativamente. Para a temperatura de $35^{\circ} \mathrm{C}$ foi necessário o volume de água igual a 3,02 vezes o peso do substrato seco para se obter um máximo de germinação (67\%). (Figura 1). O volume de água equivalente a 2,0 vezes o peso do papel foi responsável pelos menores percentuais de germinação em ambas as temperaturas utilizadas $\left(30^{\circ} \mathrm{C}\right.$ e $\left.35^{\circ} \mathrm{C}\right)$, sendo que na temperatura de $35{ }^{\circ} \mathrm{C}$ estes percentuais foram inferiores a $20 \%$, enquanto que na temperatura de $30^{\circ} \mathrm{C}$ esta percentagem de germinação encontra-se em torno de $50 \%$.

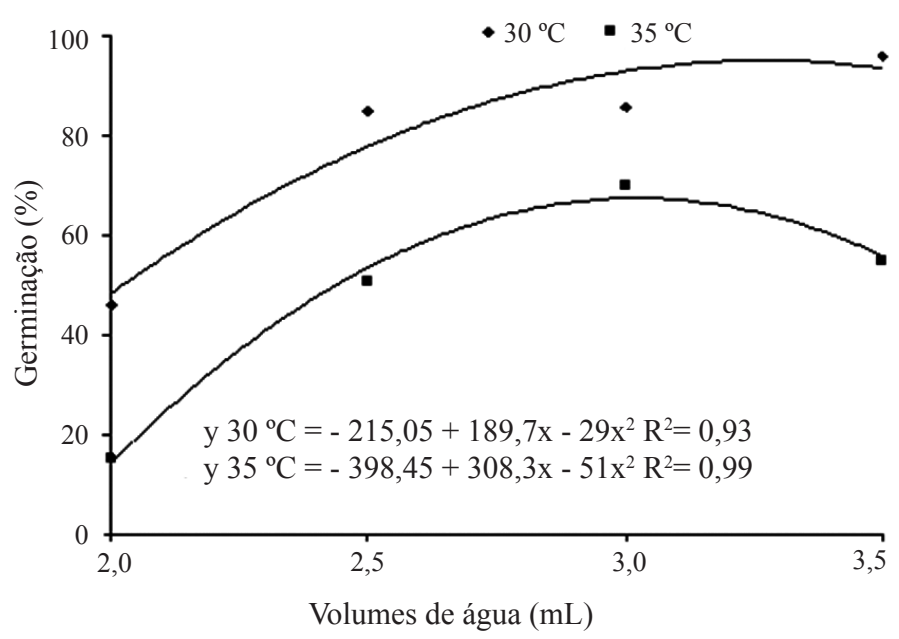

FIGURA 1. Germinação (\%) de sementes de Amburana cearensis (Allemão) A.C. Smith, submetidas a diferentes temperaturas e volumes de água no substrato.

Estes resultados mostram que o volume de 2,0 vezes o peso do papel é insuficiente para condução do teste de germinação e que a espécie $A$. cearensis requer volumes maiores de água para desencadear o processo germinativo. Para a temperatura de $35{ }^{\circ} \mathrm{C}$ verificou-se que a mesma foi muito elevada, favorecendo a deterioração das sementes, e embora houvesse emissão de raiz primária, não o desenvolvimento subsequente, impedindo a formação de plântulas normais, o que limita a área onde essa espécie pode estabelecer-se e regenerar a vegetação. Para a realização do teste de germinação Amburana acreana (Ducke) A. C. Sm. a temperatura mais adequada é $30^{\circ} \mathrm{C}$ (Bello et al., 2008).

Diferente do que foi verificado no presente trabalho, Ramos et al. (2006b) mencionaram que as temperaturas não influenciaram no percentual de germinação de sementes de Schizolobium amazonicum Huber ex Ducke. Para a germinação das sementes de Ochroma pyramidale (Cav. ex Lam.) Urban recomenda-se a temperatura de $30{ }^{\circ} \mathrm{C}$ com o volume de água de 1,5 vezes o peso do papel, e a temperatura de $35^{\circ} \mathrm{C}$ com a quantidade de água de 3,0 vezes o peso do papel (Ramos et al., 2006a). Para sementes de Parkia platycephala Benth., verificou-se que a utilização dos volumes de água equivalente a 2,$0 ; 2,5 ; 3,0$ e 3,5 vezes o peso do papel e as temperaturas de 25,30 e $35^{\circ} \mathrm{C}$ proporcionaram uma melhor expressão do potencial fisiológico das sementes (Gonçalves et al., 2008). Conforme Vicente et al. (1969) a germinação mais favorável pode não ser induzida por somente um volume de água, mas por diversos volumes que ocupam uma faixa de amplitude específica, conforme a espécie.

Para as sementes de Tabebuia capitata (Bur. \& K. Schum.) Sandw., Castro (2003) verificou que as temperaturas de $30{ }^{\circ} \mathrm{C}$ e $35{ }^{\circ} \mathrm{C}$ resultaram nas maiores porcentagens de germinação. Borges e Rena (1993) constataram que sementes de um grande número de espécies florestais subtropicais e tropicais, mostram seu potencial máximo de germinação na faixa de temperatura entre 20 e $30^{\circ} \mathrm{C}$.

Os dados referentes ao vigor, determinado pela primeira contagem de germinação das sementes de A. cearensis são apresentados na Figura 2. Verificou-se que o maior percentual de plântulas normais (59\%) foi obtido quando as sementes foram submetidas à temperatura de $30{ }^{\circ} \mathrm{C}$, no volume de água igual a 3,08 vezes o peso do papel. As sementes acondicionadas no substrato papel toalha sob influência dos volumes de água estudados, não se ajustaram a nenhum modelo de regressão polinomial, para o ambiente com temperatura de $35{ }^{\circ} \mathrm{C}$, sendo os resultados expressos em médias, indicando que esta variável não foi influenciada pelos tratamentos testados.

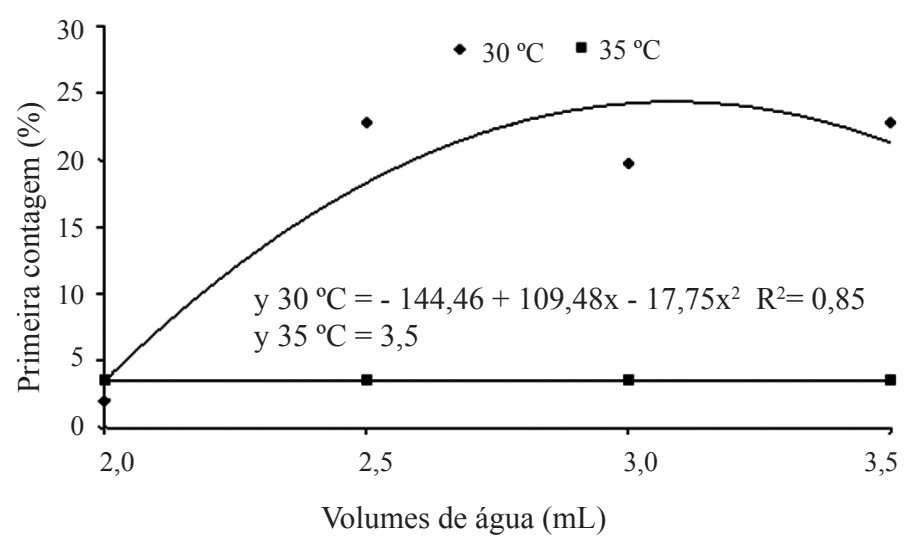

FIGURA 2. Primeira contagem de germinação (\%) de sementes de Amburana cearensis (Allemão) A.C. Smith, submetidas a diferentes temperaturas e volumes de água no substrato. 
Para os resultados de índice de velocidade de germinação (IVG) verificou-se um aumento linear na temperatura de 30 ${ }^{\circ} \mathrm{C}$, em função do aumento do volume de água utilizado para umedecer o substrato (Figura 3). Já na temperatura de $35^{\circ} \mathrm{C}$ foi necessário o volume de água igual a 3,04 vezes o peso do papel para se obter o maior IVG.

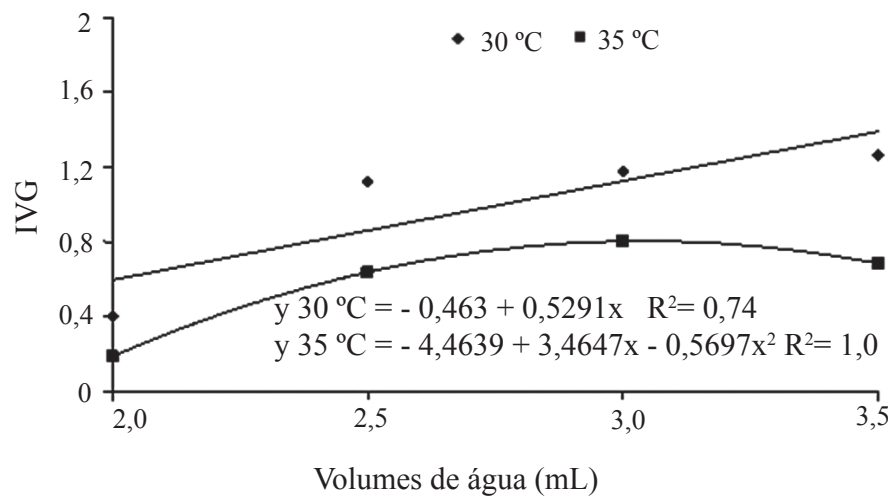

FIGURA 3. Índice de velocidade de germinação de sementes de Amburana cearensis (Allemão) A.C. Smith, obtido em diferentes temperaturas e volumes de água no substrato.

$\mathrm{Na}$ temperatura adequada à germinação $\left(30^{\circ} \mathrm{C}\right)$ haverá uma maior velocidade de embebição da água, com o rápido amolecimento do tegumento e subsequente protrusão da radícula, caracterizando a condiçãoideal para que desencadeie o processo germinativo e estabelecimento das plântulas. Já a temperatura de $35{ }^{\circ} \mathrm{C}$ deve ter sido elevada o suficiente para causar injúrias ao sistema de membranas celulares, reduzindo a porcentagem de germinação e a velocidade de germinação. Os dados corroboram com os obtidos por Ramos et al. (2006b) em que o índice de velocidade de germinação de sementes de Schizolobium amazonicum Huber ex Ducke foi influenciado pela temperatura e volume de água no substrato.

Em sementes de Largenaria siceraria (Mol.) Standi., a menor velocidade de germinação foi observada quando se utilizou a proporção de água equivalente a 3,0 vezes o peso do substrato (Bisognin et al., 1991). Os resultados de índice de velocidade de germinação não apresentaram diferença significativa para os volumes de água no substrato, para sementes de Ochroma pyramidale (Cav. ex Lam.) Urban (Ramos et al., 2006a), bem como para Dinizia excelsa Ducke (Varela et al., 2005). Para Parkia platycephala Benth., houve um aumento linear da germinação e do índice de velocidade de germinação com o aumento da quantidade de água no substrato $(2,0 ; 2,5 ; 3,0$ e 3,5 vezes o peso do substrato), quando utilizou a temperatura de $20{ }^{\circ} \mathrm{C}$ (Gonçalves et al., 2008).

O comprimento das plântulas de $A$. cearensis (Figura 4), em ambas as temperaturas testadas $\left(30\right.$ e $\left.35{ }^{\circ} \mathrm{C}\right)$, aumentou linearmente em função do aumento do volume de água empregado para umedecer o substrato. Entretanto, na temperatura de $35^{\circ} \mathrm{C}$ verifica-se que houve emissão de raiz primária, mas o desenvolvimento subsequente desta estrutura foi limitado, sendo observado um ressecamento do ápice das raízes, independente do volume de água aplicado. Este fato pode ser explicado pelas temperaturas elevadas que favorecem a deterioração das sementes, como verificado por Bello et al. (2008) em sementes de Amburana acreana (Ducke) A. C. Sm. à $40{ }^{\circ} \mathrm{C}$.

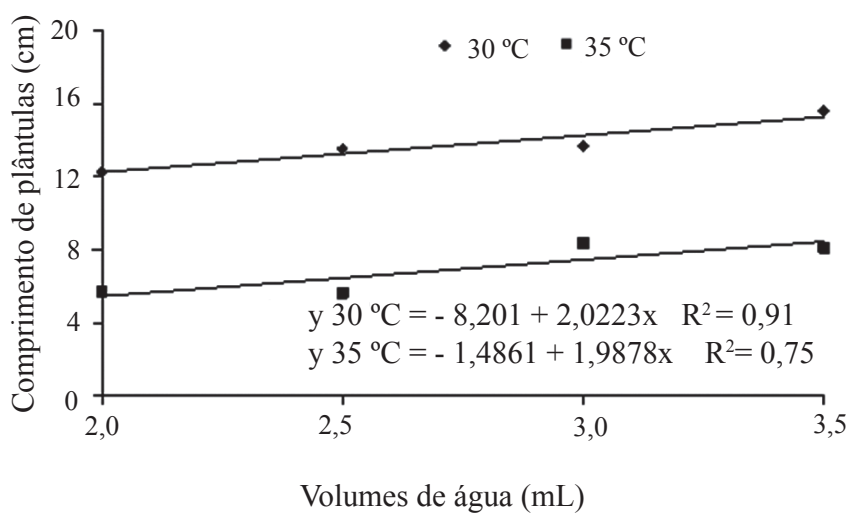

FIGURA 4. Comprimento de plântulas oriundas de sementes de Amburana cearensis (Allemão) A.C. Smith, submetidas a diferentes temperaturas e volumes de água no substrato.

De acordo com Nakagawa (1999), a diferença de $1{ }^{\circ} \mathrm{C}$ na temperatura durante o teste de germinação terá, provavelmente, efeito desprezível na porcentagem final de germinação, porém esta mesma diferença proporcionará considerável efeito no comprimento da raiz das plântulas. Estes resultados foram evidenciados no presente estudo, onde se observa que o comprimento da plântula (Figura 4), em especial a raiz primária foi mais influenciado pela elevação da temperatura do que a porcentagem de germinação total (Figura 1).

O desenvolvimento da raiz primária das plântulas oriundas de sementes de Schizolobium amazonicum Huber 
ex Ducke, para as quantidades de água de 1,5;2,0 e 2,5 vezes o peso do papel não foi influenciado pelas temperaturas de 25,30 e $35{ }^{\circ} \mathrm{C}$ (Ramos et al., 2006b). Os melhores tratamentos para o desenvolvimento da raiz primária das plântulas de Ochroma pyramidale (Cav. ex Lam.) Urban, são a temperatura de $30{ }^{\circ} \mathrm{C}$, com a quantidade de água de 1,5 vezes o peso do papel, e a temperatura de $35^{\circ} \mathrm{C}$ com a quantidade de água de 3,0 vezes o peso do papel (Ramos et al., 2006a).

Quanto ao comprimento do hipocótilo, as temperaturas mais altas $\left(30\right.$ e $\left.35^{\circ} \mathrm{C}\right)$ e os volumes de água acima de 2,0 vezes o peso do papel apresentam melhores resultados para espécie Dinizia excelsa Ducke (Varela et al., 2005). As maiores médias do comprimento do hipocótilo de plântulas de Jacaranda copaia D. Don foi obtido quando as sementes foram submetidas às temperaturas de $25 \mathrm{e} 30^{\circ} \mathrm{C}$, não havendo diferença estatística na quantidade de água e na interação entre os fatores (Abensur et al. 2007).

Avaliando-se o vigor das sementes de A. cearensis determinado pela massa seca de plântulas (Figura 5) observou-se que não houve influência dos diferentes volumes de água utilizados para umedecer o substrato, relacionando apenas a interferência das temperaturas, sob esta determinação do vigor. Observou-se que o maior conteúdo de massa seca de plântulas $(0,067 \mathrm{~g})$ foi obtido na temperatura de $30^{\circ} \mathrm{C}$ e na temperatura de $35^{\circ} \mathrm{C}$ foi registrado conteúdo médio de massa seca de 0,027 g. Para a massa seca do hipocótilo das plântulas de Apeiba tibourbou Aubl., os melhores resultados foram obtidos quando se utilizaram as temperaturas constantes de 30 e $35^{\circ} \mathrm{C}$ (Pacheco et al., 2007).

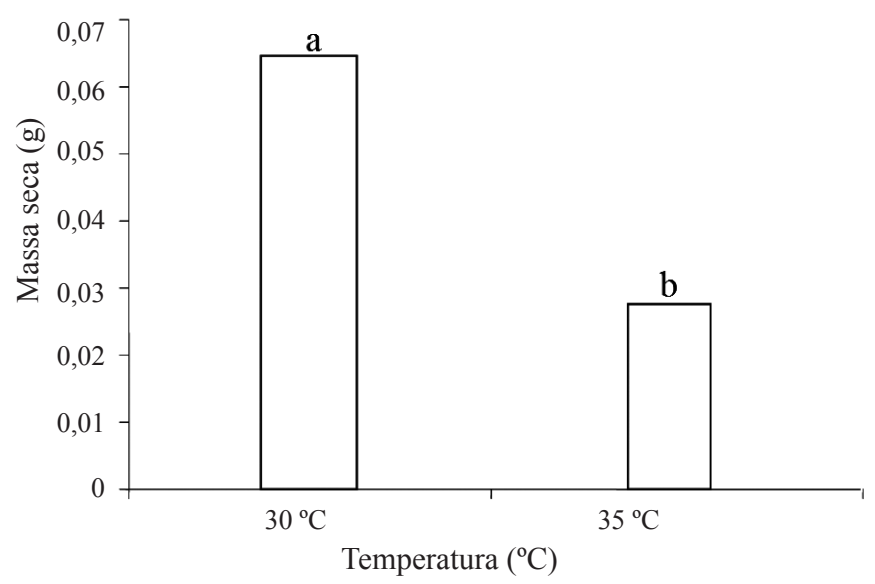

FIGURA 5. Valores médios da massa seca das plântulas de oriundas de sementes de Amburana cearensis (Allemão) A.C. Smith, submetidas a diferentes temperaturas.

\section{CONCLUSÕES}

A temperatura de $30{ }^{\circ} \mathrm{C}$ e o volume de água de 3,5 vezes o peso do papel é a combinação mais adequada para a condução dos testes de germinação e vigor das sementes de Amburana cearensis.

\section{REFERÊNCIAS}

ABENSUR, F.O.; MELO M.F.F.; RAMOS, M.B.P.; VARELA, V.P.; BATALHA, L.P. Tecnologia de sementes e morfologia da germinação de Jacaranda copaia D. Don (Bignoniaceae). Revista Brasileira de Biociências, v.5, supl. 2, p.60-62, 2007.

BELLO, E.P.B.C.S; ALBUQUERQUE, M.C.F.; GUIMARÃES, S.C.; MENDONÇA, E.A.F. Germinação de sementes de Amburana acreana (Ducke) A. C. Sm. submetidas a diferentes condições de temperatura e de estresse hídrico. Revista Brasileira de Sementes, v.30, n.3, p.16-24, 2008.

BEZERRA, A.M.E; CANUTO, K.M.; SILVEIRA, E.R. Estudo fitoquímico de espécimes jovens de Amburana cearensis A.C. Smith. 29a Reunião Anual da Sociedade Brasileira de Química, 2005.2p.

BISOGNIN, D.A.; IRIGON, D.L.; MARTINAZZO, A.A. Teste de germinação em porongo - Lagenaria siceraria (Mol.) Standi. Ciência Rural, v.21, n.2, p.159-167, 1991.

BORGES, E.E.L.; RENA, A.B. Germinação de sementes. In: AGUIAR, I.B.; PIÑA-RODRIGUES, F.M.C.; FIGLIOLIA, M.B. (Coord.). Sementes florestais tropicais, Brasília, DF: ABRATES, 1993. cap.3-6, p.83-135.

BRASIL. Ministério da Agricultura e Reforma Agrária. Secretaria Nacional de Defesa Agropecuária. Departamento Nacional de Defesa Vegetal. Coordenação de Laboratório Vegetal. Regras para análise de sementes. Brasília, DF, 1992. 365p.

CANUTO, K.M. Contribuição ao conhecimento químico de plantas do Nordeste: Herisantia tiubae (K. Schumann) Briz e Amburana cearensis (Fr. Allem.) A. C. Sm. 2002. 123f. Dissertação (Mestrado em Química Orgânica ) Universidade Federal do Ceará, 2002.

CARVALHO, N.M.; NAKAGAWA, J. Sementes: ciência, tecnologia e produção. 4.ed. FUNEP: Jaboticabal, 2000. 588p.

CASTRO, M.N. Influência de diferentes temperaturas na germinação de sementes de ipê (Tabebuia capitata (Bur. \& K. Schum.) Sandw. Instituto de Tecnologia da Amazônia, 2003. 24 p. 
COIMBRA, R.A.; TOMAZ, C.A.; MARTINS, C.C.; NAKAGAWA,J.Testedegerminaçãocomacondicionamento dos rolos de papel em sacos plásticos. Revista Brasileira de Sementes, v.29, n.1, p.92-97, 2007.

FIGLIOLIA, M.B., OLIVEIRA, E.C.; PIÑA-RODRIGUES, F.C.M. Análise de sementes. In: AGUIAR, I.B.; PIÑARODRIGUES, F.C.M.; FIGLIOLIA, M.B. (Coord.) Sementes florestais tropicais. Brasília, DF: ABRATES, 1993. p.137-174.

GENTIL, D.F.O.; TORRES, S.B. Umedecimento do substrato e germinação de sementes de maxixe (Cucumis anguria L.). Revista Brasileira de Sementes, v.23, n.2, p.113-116, 2001

GONÇALVES, E.P.; FRANCA, P.R.C.; ALVES, E.U.; BRUNO, R.L.A.; GUEDES, R.S. Potencial fisiológico de sementes de Parkia platycephala Benth. CONGRESSO DE PESQUISA E INOVAÇÃO DA REDE NORTE NORDESTE DE EDUCAÇÃO TECNOLÓGICA, 3., 2008, Fortaleza 2008. Anais..., Fortaleza - CE, 2008. (Cd Rom).

IBAMA. Instituto Brasileiro de Meio Ambiente e dos Recursos Naturais Renováveis. Lista oficial de espécies da flora brasileira ameaçada de extinção. Portaria $\mathrm{n}^{\circ} .37-\mathrm{N}$ de 3 de abril de 1992. Disponível em: < http://www.ibama.gov. br>. Acesso em: 14 dez. 2008.

LORENZI, H; MATOS, F.J.A. Plantas medicinais no Brasil: nativas e exóticas. São Paulo: Instituto Plantarum de Estudos da Flora Ltda, 2002. 512p.

MAGUIRE, J.D. Speed of germination aid in selection and evaluation for seedling emergence and vigor. Crop Science, v.2, n.2, p.176-177, 1962.

NAKAGAWA, J. Testes de vigor baseados no desempenho das plântulas. In: KRZYZANOWSKI, F.C.; VIEIRA, R.D.;
FRANÇA NETO, J.B. (Ed.). Vigor de sementes: conceitos e testes. Londrina: ABRATES, 1999. p.1-24.

NOVEMBRE, A.D.L.C.; MARCOS FILHO, J. Estudo da metodologia para condução do teste de germinação em sementes de algodão deslintadas mecanicamente. Revista Brasileira de Sementes, v.21, n.2, p.187-193, 1999.

PACHECO, M.V.; MATOS, V.P.; FERREIRA, R.L.C.; FELICIANO, A.L.P. Germinação de sementes de Apeiba tibourbou Aubl. em função de diferentes substratos e temperaturas. Scientia Forestalis, n.73, p.19-25, 2007.

RAMOS, M.B.P.; VARELA, V.P.; MELO, M.F.F. Influência da temperatura e da água sobre a germinação de sementes de paricá (Schizolobium amazonicum Huber ex Ducke Leguminosae - Caesalpinoideae). Revista Brasileira de Sementes, v.28, n.1, p.163-168, 2006b.

RAMOS, M.B.P.; VARELA, V.P.; MELO, M.F.F. Influência da temperatura e da quantidade de água no substrato sobre a germinação de sementes de Ochroma pyramidale (Cav. ex Lam.) Urban (pau-de-balsa). Acta Amazonica, v.36, n.1, p.103-106, 2006a.

TANAKA, M.A.S.; MARIANO, M.I.A.; LEÃO, N.V.M. Influência da quantidade de água no substrato sobre a germinação de sementes de amendoim. Revista Brasileira de Sementes, v.13, n.1, p.73-76, 1991.

VARELA, V.P.; RAMOS, M.B.P.; MELO, M.F.F. Umedecimento do substrato e temperatura na germinação de sementes de angelim-pedra (Dinizia excelsa Ducke). Revista Brasileira de Sementes, v.27, n.2, p.130-135, 2005.

VICENTE, M.; NORONHA, A.; SILBERSCHMIDT, K. Substrate moisture levels for germination testing of some agricultural seeds. Anais da Academia Brasileira de Ciências, v.41, n.4, p.633-639, 1969. 